\title{
Interfacial design of $\mathrm{Cu} / \mathrm{SiC}$ composites prepared by Powder Metallurgy for Heat sink applications
}

\author{
Th. Schubert ${ }^{1 *}$, A. Brendel ${ }^{2}$, K. Schmid ${ }^{2}$, Th. Koeck ${ }^{2}$, Ł. Ciupiński ${ }^{3}$, W. Zielinski ${ }^{3}$, T. \\ Weißgärber ${ }^{1}$, B. Kieback ${ }^{1}$ \\ ${ }^{1}$ Fraunhofer-Institute for Manufacturing and Advanced Materials, Dept. Powder Metallurgy and \\ Composite, Materials, Winterbergstr. 28., D-01277 Dresden, Germany \\ ${ }^{2}$ Max Planck Institute for Plasma Physics, Boltzmannstraße 2, 85748 Garching, Germany \\ ${ }^{3}$ Faculty of Materials Science and Engineering, Warsaw University of Technology, ul. Woloska 141, \\ 02-501 Warsaw, Poland.
}

\begin{abstract}
In order to dissipate the heat generated in electronic packages, suitable materials must be developed as heat spreaders or heat sinks. Metal matrix composites (MMCs) offer the possibility to tailor the properties of a metal $(\mathrm{Cu})$ by adding an appropriate reinforcement phase (SiC) to meet the demands for high thermal conductivities in thermal management applications. Copper/SiC composites have been produced by powder metallurgy. Silicon carbide is not stable in copper at the temperature needed for the fabrication of $\mathrm{Cu} / \mathrm{SiC}$. The major challenge in development of $\mathrm{Cu} / \mathrm{SiC}$ is the suppression of this reaction between copper and $\mathrm{SiC}$. Improvements in bonding strength and thermo-physical properties of the composites have been achieved by a vapour deposited molybdenum coating on $\mathrm{SiC}$ powders to control the detrimental interfacial reactions.
\end{abstract}

Keywords: copper composites, powder metallurgy, thermal management, heat sinks, electronics.

\section{Introduction}

Electronic packaging involves interconnecting, powering, protecting and cooling of semiconductor circuits for use in a variety of electronic applications. In a power electronic insulated gate bipolar transistor (IGBT) module the heat is generated in the silicon chips during power on state. The maximum power loss is in the range of $100 \mathrm{~W} / \mathrm{cm}^{2}$ (active silicon area on the chip) for low voltage modules to $200 \mathrm{~W} / \mathrm{cm}^{2}$ for high voltage modules. Silicon transistors

\footnotetext{
* To whom correspondence should be addressed (phone: +49(0)351/2537-346, fax: +49(0)351/2537-399, e-mail: Thomas.Schubert@ifam-dd.fraunhofer.de)
} 
operate with little change only up to $150^{\circ} \mathrm{C}$, the specified maximum junction temperature for most Si transistors. Therefore the packaging has to provide effective cooling to stay within the operating temperature limit. Furthermore, effective cooling generally increases the reliability of the components. Substrate materials with high thermal conductivity are required to work as heat spreader or heat sinks removing heat from local hot spots quickly. A typical substrate material for discrete power components is copper, because it has a very high thermal conductivity, a low electrical resistance, a lower coefficient of thermal expansion (CTE) than aluminum and can easily be formed or machined into complicated leadframes or base plates. Unfortunately, the thermal expansion of copper is about four times higher than that of the semiconductor silicon. The main type of failure of power modules is thermal fatigue of the soft solder joints, owing to the different thermal expansion coefficients of semiconductor chips and packaging materials Therefore, materials having reduced coefficient of thermal expansion (CTE) mismatches with $\mathrm{Si}$, InP or GaAs in combination with a high thermal conductivity are required for heat sinks and heat spreaders. Comprehensive reviews of this field are given by Zweben [1] and German [2]. State of the art power modules are built with an $\mathrm{AlSiC}$ base plate. $\mathrm{SiC}$ combines a thermal conductivity of about $200-300 \mathrm{~W} / \mathrm{mK}$ with a CTE of $4.510^{-6} / \mathrm{K}$, and offers a good availability, low price and possible machinability. Therefore, the use of SiC particles as reinforcements in copper based composites is considered very attractive to meet the increasing demands for high performance heat sink materials and packages.

A silicon carbide reinforced copper composite is the aim of several investigations [3-5]. Unfortunately, silicon carbide is not stable in contact with copper at elevated temperatures. Silicon is partially dissolved in copper forming a copper(silicon) solid solution and pure carbon remains at the $\mathrm{Cu} / \mathrm{SiC}$ interface. Dissolved silicon reduces dramatically the thermal and electrical conductivities of $\mathrm{Cu} / \mathrm{SiC}$ composites. Therefore, diffusion barriers are necessary to prevent the detrimental interfacial reaction between copper and SiC. The literature has shown various diffusion barriers including refractory metals (e.g. Ta, W) [5-7], nitrides or carbides (e.g. TiN, TaN) [8-10] and compounds (e.g. TiW) [11-14]. 
In this study the effectiveness of a vapour deposited molybdenum layer onto the $\mathrm{SiC}$ powder was investigated. The differences between coated and uncoated powders will be discussed. The thermo-physical properties of the composites will be displayed and discussed as a function of the revealed interfacial microstructures.

\section{Experimental}

To investigate the interactions between $\mathrm{Cu}, \mathrm{SiC}$ and a $\mathrm{Mo}$ interlayer two kinds of samples were used: a planar silicon carbide substrate coated with $\mathrm{Cu}$ or $\mathrm{Cu} / \mathrm{Mo}$ and copper composites reinforced with uncoated and Mo-coated SiC particles respectively.

Planar SiC substrates were coated in a magnetron sputter device with nominally $200 \mathrm{~nm}$ Mo and $200 \mathrm{~nm} \mathrm{Cu}$. In a first step Mo was sputtered with $300 \mathrm{~W}$ for 9 minutes. In a second step, without breaking the vacuum, $\mathrm{Cu}$ was sputtered with $300 \mathrm{~W}$ for 4 minutes. One sample was prepared without a Mo interlayer for comparison. Subsequently these samples were tempered in a UHV oven (base pressure $10^{-9} \mathrm{mbar}$ ) at $550^{\circ} \mathrm{C}, 650^{\circ} \mathrm{C}$ for one hour and at $850^{\circ} \mathrm{C}$ for 30 minutes. After tempering the depth profiles of $\mathrm{Si}, \mathrm{C}, \mathrm{Mo}$ and $\mathrm{Cu}$ were measured using ion Rutherford backscattering (RBS) with $2 \mathrm{MeV} \mathrm{He}$ and X-ray diffraction (XRD). RBS is a quantitative method that can be used as a means to perform a depth profile of the composition of a sample. The depth profiles were determined from the experimental backscattering data by using SIMNRA [15]. SIMNRA is a simulation tool that calculates the resulting RBS spectrum based on a given composition depth profile. The composition depth profile is input by the user and is varied until the simulated RBS spectrum matches the measured RBS spectrum. The accuracy is limited by the counting statistics and the accuracy of the ion beam current measurement. For the $\mathrm{Cu} / \mathrm{Si} / \mathrm{C}$ system invesitgated here the accuracy of the composition measurement is in the order of $1 \%$.

The copper/SiC composites have been produced by powder metallurgy. A pure copper powder produced by wet chemical precipitation with $\mathrm{d}_{50}$ of $6 \mu \mathrm{m}$ and a purity $>99.9 \%$ was used. The used particle reinforcements are uncoated or PVD pre-coated SiC/F240-green $(30-70 \mu \mathrm{m})$ or $\mathrm{SiC} / \mathrm{F} 80$-green $(150-210 \mu \mathrm{m})$ with molybdenum. The coating by sputtering was performed at 
the Coimbra University, Portugal. If PVD method are used to coat fine particles below about $100 \mu \mathrm{m}$ additional methods are necessary to avoid a clustering or shadowing of the individual particles. During the deposition the powders were continually moved by vibration and translation motions in order to obtain homogeneous coatings [16]. A coating thickness of about $180 \mathrm{~nm}$ can be estimated from density measurements using He-pycnometry (type Accupyc 1330, manufactured by Micromeritics, USA). The coated SiC powder reveals dense and well adherent molybdenum coatings on the $\mathrm{SiC}$ powder particles.

Subsequently, the copper powders were mixed with the ceramic particles to prepare composites with about 40vol\% reinforcement. These composites were fabricated by pressure-assisted sintering using a hot press with indirect resistance heating (type HPW 315/400, manufactured by FCT Systeme GmbH, Germany).

The composites were studied by SEM and TEM. The corresponding TEM specimens were prepared using standard procedure involving dimpling and ion polishing. Thin foils of a uniform thickness were also prepared by Focused Ion Beam (FIB) milling, that enabled EDS analysis of elements distribution across the interface.

The bulk density of the composites was measured by using a method based on Archimedes' law and compared with the theoretical density. The measurement of the coefficients of thermal expansion (CTE) was performed in a Netzsch dilatometer under the following conditions: temperature range $25-300^{\circ} \mathrm{C}$; heating rate $5 \mathrm{~K} / \mathrm{min}$; argon atmosphere.

The thermal conductivity was measured by Xenon pyrometry with the Nanoflash of the company Netzsch, Germany.

\section{Results and discussion}

\section{Thermo-physical properties}

The results regarding the thermo-physical properties of the manufactured $40 \mathrm{vol} \% \mathrm{SiC}$ reinforced $\mathrm{Cu}$ composites by using uncoated and pre-coated $\mathrm{SiC}$ particles are presented in Table 1. 
Table 1. Comparison of the thermo-physical properties of different $\mathrm{Cu} / \mathrm{SiC}$ composites.

\begin{tabular}{|l|c|c|c|c|}
\hline Material & $\begin{array}{c}\text { Thermal } \\
\text { Diffusivity } \\
\mathrm{mm}^{2} / \mathrm{s}\end{array}$ & $\begin{array}{c}\text { Specific heat } \\
\mathrm{J} / \mathrm{gK}\end{array}$ & $\begin{array}{c}\text { Thermal } \\
\text { conductivity at } \mathrm{RT}\end{array}$ & $\begin{array}{c}\mathrm{CTE}\left(30-100^{\circ} \mathrm{C}\right) \\
\mathrm{W} / \mathrm{mK}\end{array}$ \\
\hline $\mathrm{Cu} / \mathrm{SiC}(\mathrm{F} 240)$ & 72 & 0.468 & 222 & 14.5 \\
\hline $\mathrm{Cu} / \mathrm{SiC}^{\mathrm{Mo}}(\mathrm{F} 240)$ & 93 & 0.467 & 288 & 10.6 \\
\hline $\mathrm{Cu} / \mathrm{SiC}^{\mathrm{Mo}}(\mathrm{F} 80)$ & 102 & 0.466 & 306 & 11.2 \\
\hline
\end{tabular}

The measured thermal conductivity of $\mathrm{Cu} / \mathrm{SiC}$ made using $\mathrm{SiC}$ without a protective barrier coating is very low. The experimentally observed value is lower than the theoretically predicted value of about $320 \mathrm{~W} / \mathrm{mK}$, but it is higher than that of a sintered copper powder compact with a porosity of about $40 \%$ [17]. This can be caused by a very low effective conductivity of the SiC particles due to a low interface thermal conductance or by some silicon dissolved into copper. The CTE was only reduced to about $1410^{-6} / \mathrm{K}$ compared to pure $\mathrm{Cu}$ with about $1710^{-6} / \mathrm{K}$. This insufficient reduction of CTE indicates a imperfect interface bonding between the SiC particles and the copper matrix. The thermo-physical properties of the composites with Mo-coated SiC particles are more promising. The combination of a thermal conductivity of about $300 \mathrm{~W} / \mathrm{mK}$ with a CTE of $1110^{-6} / \mathrm{K}$ was achieved. This measured CTE is comparable with the theoretically predicted value and indicates a better mechanical interface bonding by using the coated $\mathrm{SiC}$ particles. The increased thermal conductivity of the composites also demonstrates the effectiveness of the Mo barrier onto SiC.

\section{Interface characterization}

Fig. 1 shows the typical microstructure of the $\mathrm{Cu} / 40 \% \mathrm{SiC}$ (Fig. 1a) and $\mathrm{Cu} / 40 \% \mathrm{SiC}^{\mathrm{Mo}}$ (Fig. $1 \mathrm{~b}$ ) composites $\left(\mathrm{SiC}^{\mathrm{Mo}}-\mathrm{Mo}\right.$-coated $\left.\mathrm{SiC}\right)$ with the relatively homogeneous distribution of the $\mathrm{SiC}$ particles. Thin white-colored interfacial layers of molybdenum can be revealed already at 
magnification of 250 times (Fig. 1b). At higher magnification (Fig. 1c) it can be noted that the Mo coating has varying thicknesses at different sides of the $\mathrm{SiC}$ particles.

In the system planar $\mathrm{SiC}$ substrate coated with $\mathrm{Cu}$, which acts as the reference system for the optimization process, RBS measurements show no inter-diffusion up to $650^{\circ} \mathrm{C}$. At $850^{\circ} \mathrm{C}$ the silicon carbide disintegrates and the free silicon diffuses into the copper layer (Fig. 2) towards the surface of the sample. After one hour of annealing there is a content of about $15 \mathrm{at} \%$ of silicon in the copper layer calculated by using SIMNRA. Referring to the $\mathrm{Cu} / \mathrm{Si}$ phase diagram the $\mathrm{Cu}$ solubility curve shows a maximum solid solubility of $11,25 \mathrm{at} \%$ at the temperature of $842^{\circ} \mathrm{C}$, and a lot of different phases exist in this temperature range [18]. The X-ray diffraction pattern shows no phase formation after annealing at $850^{\circ} \mathrm{C}$. Therefore the volume content of possibly formed $\mathrm{Cu}$-Si phases can be too low to be found by XRD after annealing for one hour. The composites with uncoated $\mathrm{SiC}$ were also studied by TEM. It was also evident that the interface between the uncoated $\mathrm{SiC}$ particles and the $\mathrm{Cu}$ matrix is weak, because some fissures were observed irrespective of the TEM specimen preparation technique used (i.e. standard procedure or FIB milling) (Fig. 3).

Therefore, $\mathrm{SiC}$ decomposes to $\mathrm{Si}$ and $\mathrm{C}$ in contact with copper at elevated temperatures. $\mathrm{Si}$ is dissolved into $\mathrm{Cu}$ with a simultaneous decrease of the thermal conductivity of the matrix. According to the $\mathrm{Cu} / \mathrm{C}$ phase diagram the $\mathrm{C}$ solubility in $\mathrm{Cu}$ is negligible [18]. In addition, copper is known to be chemically inert with respect to carbon. The small wettability of carbon by copper results in low interface adhesion of this material system [19]. Therefore, the remaining carbon can prevent a sufficient interfacial bonding which is also necessary for CTE reduction.

The comparison of the measured thermo-physical values supports the use of a molybdenum coating onto the $\mathrm{SiC}$ particles to prevent the detrimental chemical reaction of $\mathrm{Cu}$ with $\mathrm{SiC}$ at the temperature $\left(950^{\circ} \mathrm{C}\right)$ used for $\mathrm{Cu} / \mathrm{SiC}$ fabrication. $\mathrm{Mo}$ and $\mathrm{Cu}$ are mutually insoluble and can form intimate composites best-known as thermal management material. Otherwise, the formation of carbides and silicides is well established as reaction products between Mo and $\mathrm{SiC}$ at elevated temperatures [20]. The release of free $\mathrm{Si}$ or $\mathrm{C}$ is not expected for the $\mathrm{Mo} / \mathrm{SiC}$ system. 
For the tempering steps as $550^{\circ} \mathrm{C}$ and $650^{\circ} \mathrm{C}$ no diffusion was found at the coated planar $\mathrm{SiC}$ substrate by RBS. For tempering at $850^{\circ} \mathrm{C}$ for 30 min strong interdiffusion was found. In Fig. 4 the depth profiles after deposition and after tempering are compared. It appears that the $\mathrm{SiC}$ has begun to disintegrate at the interface, and that $\mathrm{C}$ and Si have diffused into the Mo, potentially forming Mo carbide and silicide. Apparently, the Si diffusion into copper was effectively limited compared to the binary system $\mathrm{Cu} / \mathrm{SiC}$ (see Fig. 2). The interdiffusion between $\mathrm{Cu}$ and Mo is weak which is not unexpected since $\mathrm{Cu}$ and Mo are immiscible for temperatures below $1084^{\circ} \mathrm{C}$ according to the $\mathrm{MoCu}$ phase diagram. XRD measurements were performed with two samples, one without heat treatment and one after a heat treatment at $850^{\circ} \mathrm{C}$ to investigate the phase formation. Fig. 5 shows the XRD spectra of both samples. The specimen with heat treatment has additional peaks. Two phases were determined as $\mathrm{Mo}_{2} \mathrm{C}$ and $\mathrm{Mo}_{5} \mathrm{Si}_{3}$. It can be expected that those reactions lead to better bonding between reinforcement and matrix, but on the other hand a degradation of reinforcement properties is possible.

Figure 6 presents two TEM micrographs of the interfacial regions in the hot-pressed copper composites with Mo-coated $\mathrm{SiC}$ particles. A good adhesion of the nano-crystalline Mo coating to the $\mathrm{SiC}$ particles has been observed. HR-STEM investigations (see Figure 7), performed on the FIB processes thin foils of the interface area, confirm the SEM and TEM observations regarding the non-uniformity of the Mo coating. In addition, some porosity at the interfaces is visible. The pores are predominantly located at the $\mathrm{Cu}-\mathrm{Mo}$ interface and can result in a reduced bonding strength and thermal contact. Furthermore, the EDS analyses (Fig. 8) confirm that the Mo coating can be an effective barrier against a detrimental Si interdiffusion; no silicon was detected in the adjacent copper matrix. But, the revealed non-uniformity of the Mo coating suggests some possibilities for diffusion of interlayer elements into copper decreasing the thermal conductivity of the matrix.

\section{Conclusion}

Copper based composites containing 40 vol.\% SiC particle reinforcement were fabricated by hot pressing of powder mixtures. Composite fabrication is feasible by the proposed method using 
SiC powders coated with Mo by sputtering. Obviously, a thin Mo coating can effectively reduce the reaction between $\mathrm{SiC}$ and copper by the formation of molybdenum carbides and silicides. The control of the interfacial reaction is crucial to enable manufacturing of $\mathrm{Cu}-\mathrm{SiC}$ heat sinks with a relatively high thermal conductivity combined with a reduced thermal expansion coefficient.

However, further research activity is needed in order to

- optimise the uniformity and thickness of the intermediate Mo layers,

- increase the volume content of the $\mathrm{SiC}$ particles to achieve the target CTE values,

- optimise the processing parameters (temperature, time) to reduce the residual porosity.

Acknowledgements

The authors would like to thank Prof. B. Trindade of the Coimbra University, Portugal for supply of coated SiC powders.

This work has been performed within the framework of the Integrated European Project "ExtreMat" (contract NMP-CT-2004-500253) with financial support by the European Community. It only reflects the view of the authors and the European Community is not liable for any use of the information contained therein. 


\section{References}

[1] C. Zweben, Advanced Packaging 15 (2006) 2, 1-5.

[2] R.M. German, K.F. Hens and J.L. Johnson, The Journal of Powder Metallurgy 30 (1994) 2, 205-215.

[3] T. Weißgärber, G. Lefranc, J. Schulz-Harder, H. Meyer and O. Stöcker, Advances in Powder Metallurgy \& Particulate Materials, part 6, Metal Powder Industries Federation, Princeton, NJ, 2003, pp. 33-40.

[4] G. Sundberg, Advancing Microelectronics, Nov./Dec. (2004), 8-11.

[5] S.Y. Jang, S.M. Lee and H.K. Baik, J. Mater. Sci.: Materials for Electronics, 7 (1996) 10, 271-278.

[6] C.A. Chang, J. Appl. Phys. 67 (1990) 10, 6184-6188.

[7] H. Ono, T. Nakano and T. Ohta, Appl. Phys. Lett. 64 (1994) 12, 1511-1513.

[8] S.Q. Wang, I. Raaijmakers, B.J. Burrow, S. Suther, S. Redkar and K.B. Kim, J. Appl. Phys. 68 (1990) 10, 5176-5186.

[9] T. Laurila, K. Zeng, J.K. Kivilahti, J. Molarius and I. Suni, J. Appl. Phys. 91 (2002) 8, $5391-5399$.

[10] Y.L. Kuo, J.J. Huang, S.T. Lin, C. Lee and W.H. Lee, Materials Chemistry and Physics $80(2003) 690-695$.

[11] K. Holloway, P.M. Fryer, C. Carbral, J.M.E. Harper, P.J. Bailey and K.H. Kelleher, J. Appl. Phys. 71 (1992) 11, 5433-5444.

[12] J.S. Reid, R.Y. Liu, Paul Martin Smith, R.P. Ruiz and M-A. Nicolet, Thin Solid Films 262 (1995) 218-223.

[13] G. Sundberg, P. Paul, Ch. Sung and Th. Vasilos, Journal of Materials Science 40 (2005) 3383-3393.

[14] G. Sundberg, Pradeep Paul, Changmo Sung, Thomas Vasilos, Journal of Materials Science 41 (2006) 485-504. 
[15] M. Mayer, „SIMNRA, a Simulation Program for the Analysis of NRA, RBS and ERDA”, Proceedings of the 15th International Conference on the Application of Accelerators in Research and Industry, J. L. Duggan and I.L. Morgan (eds.), American Institute of Physics Conference Proceedings 475, p. 541 (1999).

[16] F. Simoes, B. Trindade, J.A. Santos and F.H. Froes, Proceedings of High Performance PM Conference, Coimbra, Portugal (2002).

[17] A.J. Walter and A.R. Trowell, Journal of Materials Science 6 (1971) 7, $1044-1046$.

[18] T.B. Massalski, H. Okamoto, P.R. Subramanian and L. Kacprzak, Binary Alloy Phase Diagrams, 2nd Ed., Version 1.0, ASM International, Materials Park, Ohio (1996).

[19] D.A. Mortimer and M. Nicholas, Journal of Material Science 5 (1970), 149-155.

[20] H. Schmidt-Brücken and W. Schlapp, Zeitschrift für angewandte Physik 32 (1971) 4, 307-310. 


\section{FIGURE CAPTIONS}

Figure 1. SEM images (using the BSE signal) of the cross sections of the hot-pressed $\mathrm{Cu} / 40 \% \mathrm{SiC}$ (a) and $\mathrm{Cu} / 40 \% \mathrm{SiC}^{\mathrm{Mo}}$ (b) composites showing a homogeneus distribution of the $\mathrm{SiC}$ particles and varying thickness of the Mo coating layers on the $\mathrm{SiC}$ (c).

Figure 2. Silicon edge of the RBS spectra before and after different heating steps in the system $\mathrm{SiC} / \mathrm{Cu}$.

Figure 3. TEM images of a interfacial region in the copper composite with uncoated SiC particles. TEM specimen prepared using standard procedure involving dimpling and ion polishing (a) and Focusd Ion Beam milling (b).

Figure 4. Comparison of interdiffusion depth profiles and as deposited depth profiles for $\mathrm{Cu}$ on $\mathrm{Mo}$ on $\mathrm{SiC}$.

Figure 5. XRD spectra of the system SiC-Mo-Cu before and after heat treatment

Figure 6. TEM images of interfaces in copper composites with SiC particles with uniform (a) and non-uniform (b) Mo coating.

Figure 7: HR-STEM micrographs of the interface in the Mo coated $\mathrm{SiC} / \mathrm{Cu}$ composites with different magnifications $(\mathrm{a}-10.000 / 1, \mathrm{~b}-50.000 / 1)$

Figure 8. EDS line analysis across the interface marked in Fig. $7 \mathrm{~b}$. 
Figure 1

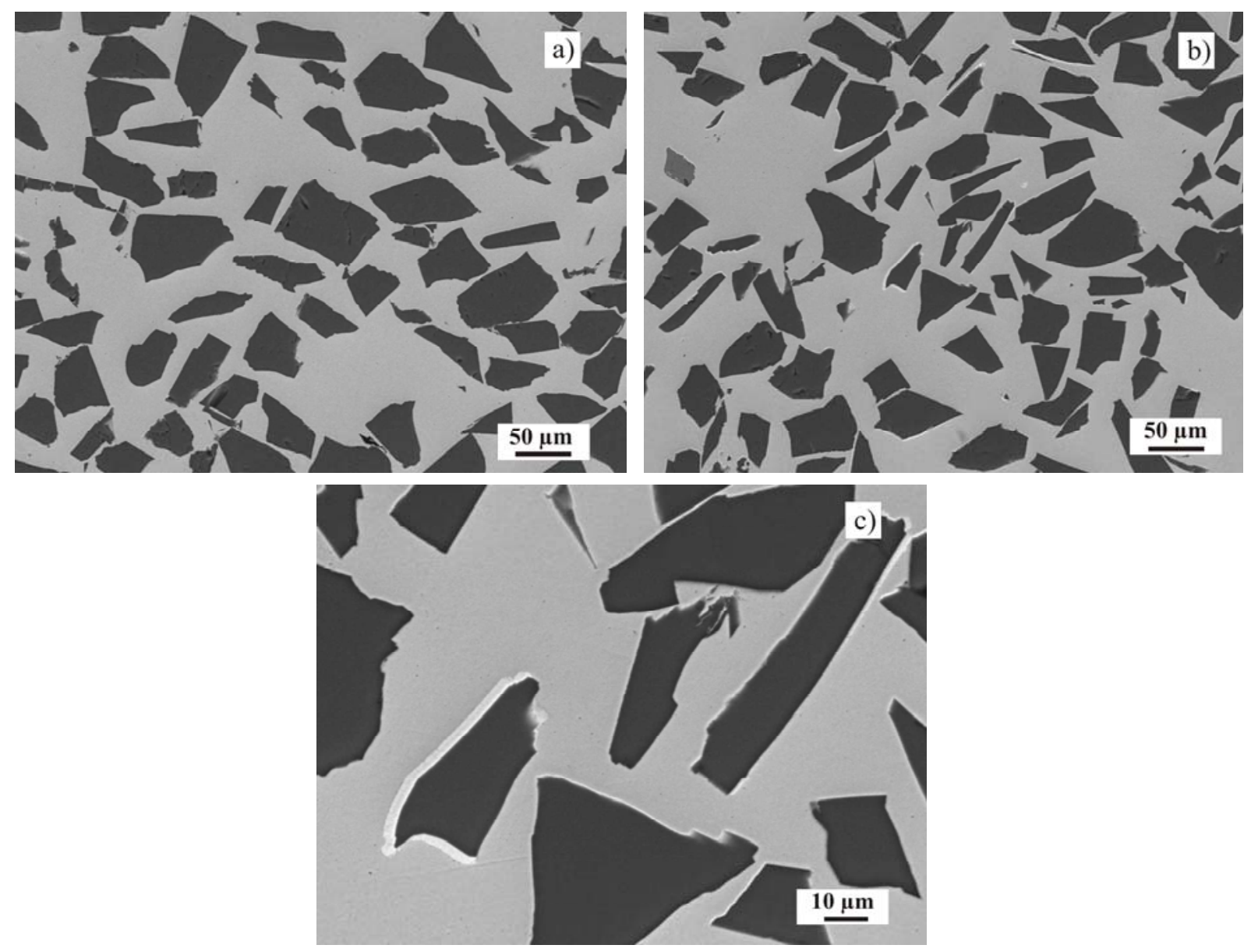

Figure 2

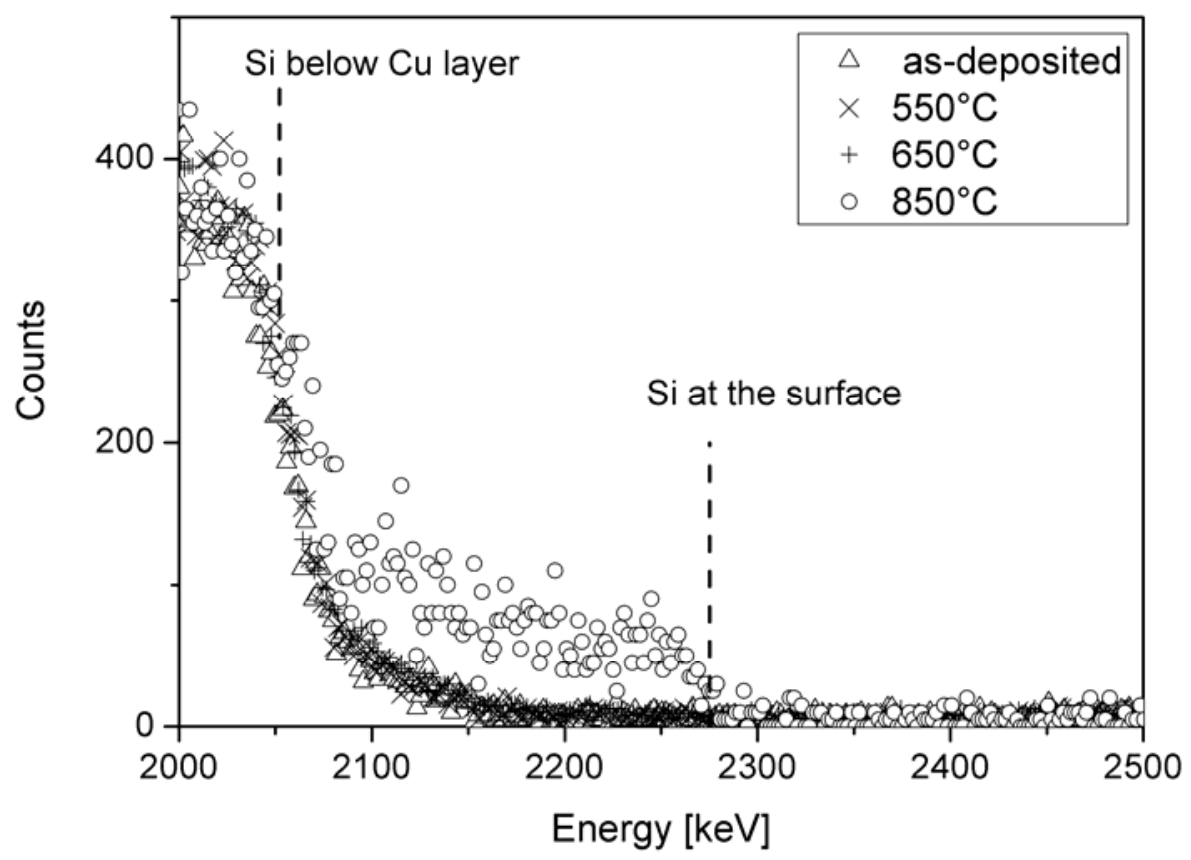


Figure 3
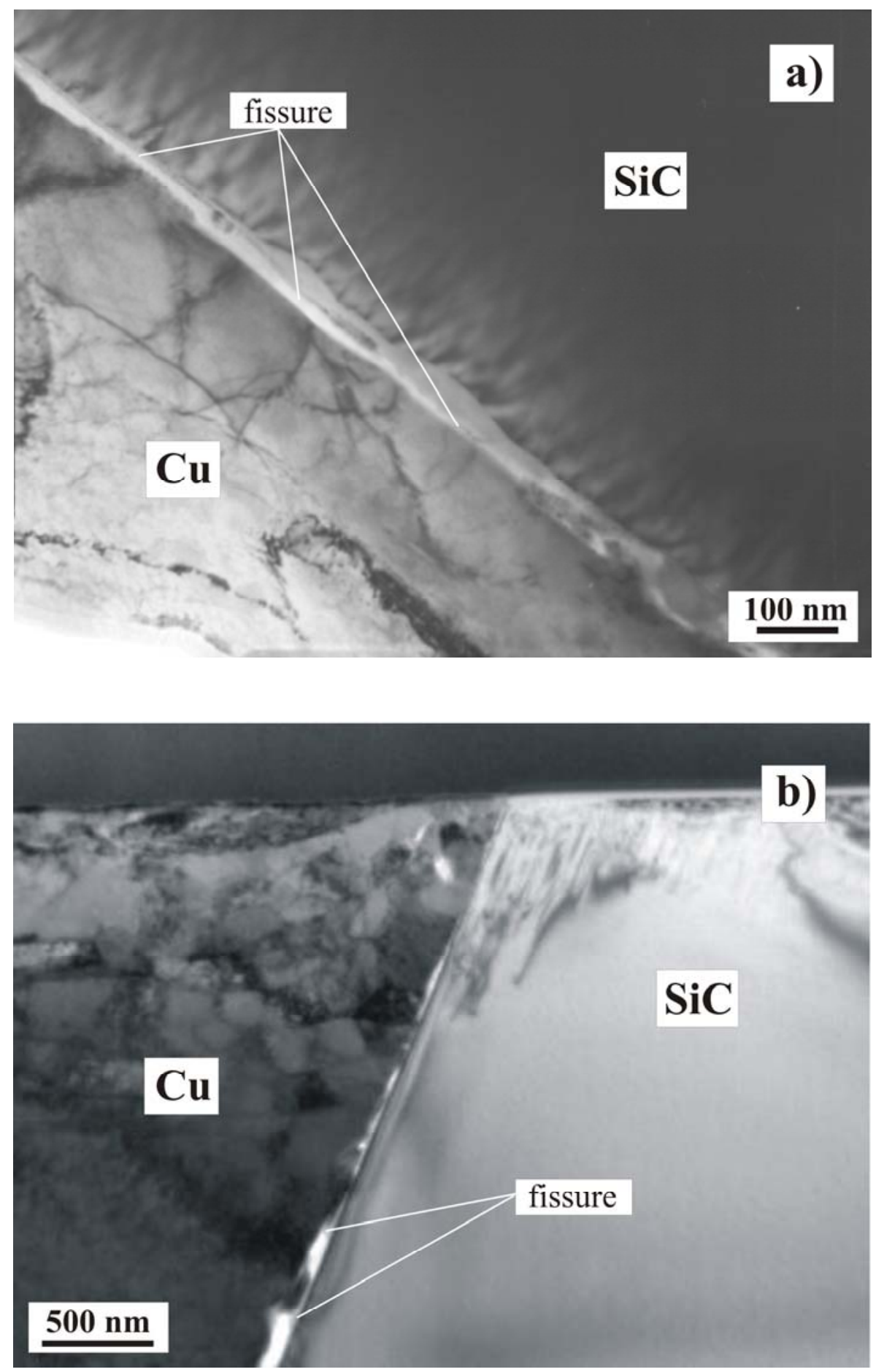
Figure 4

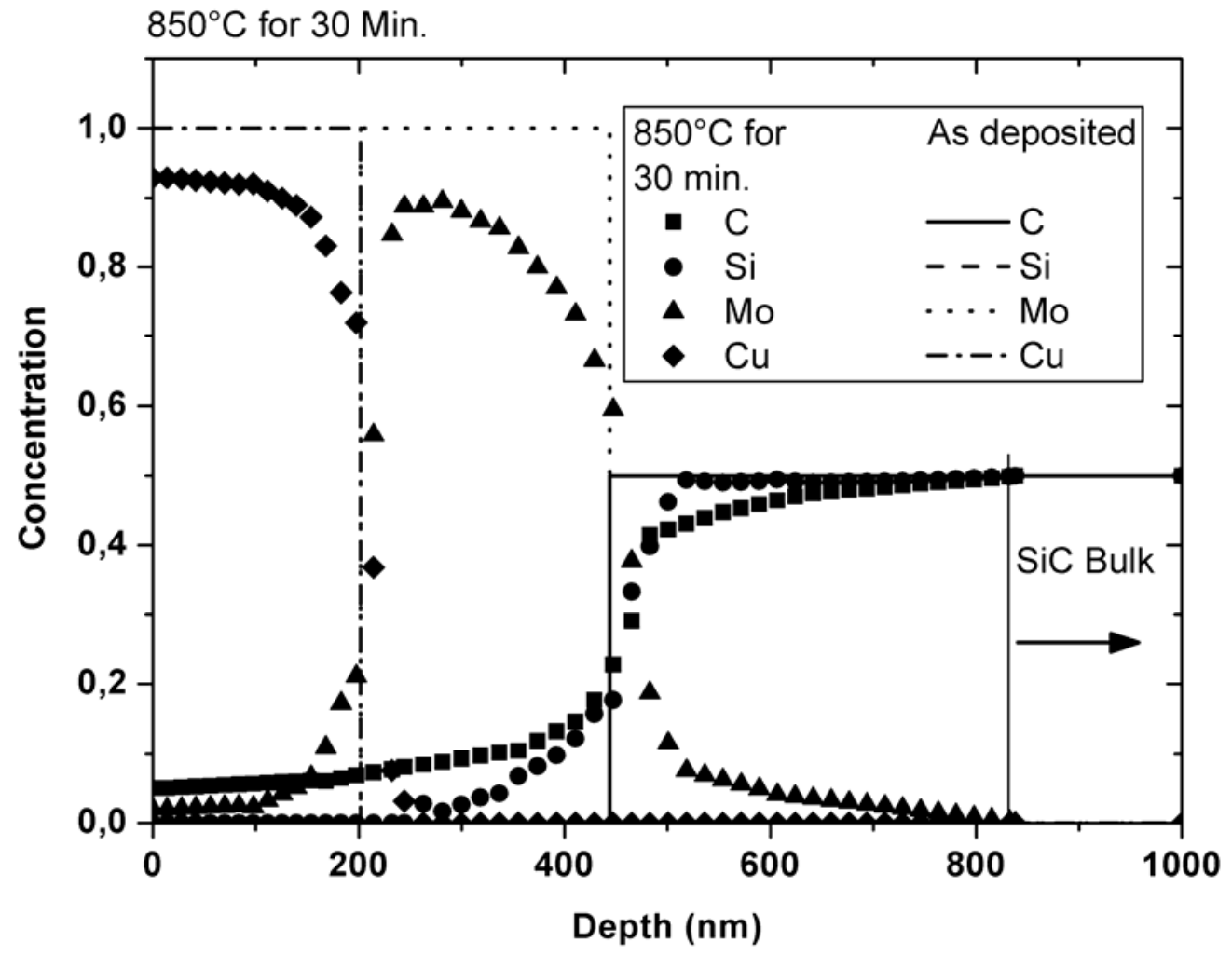

Figure 5

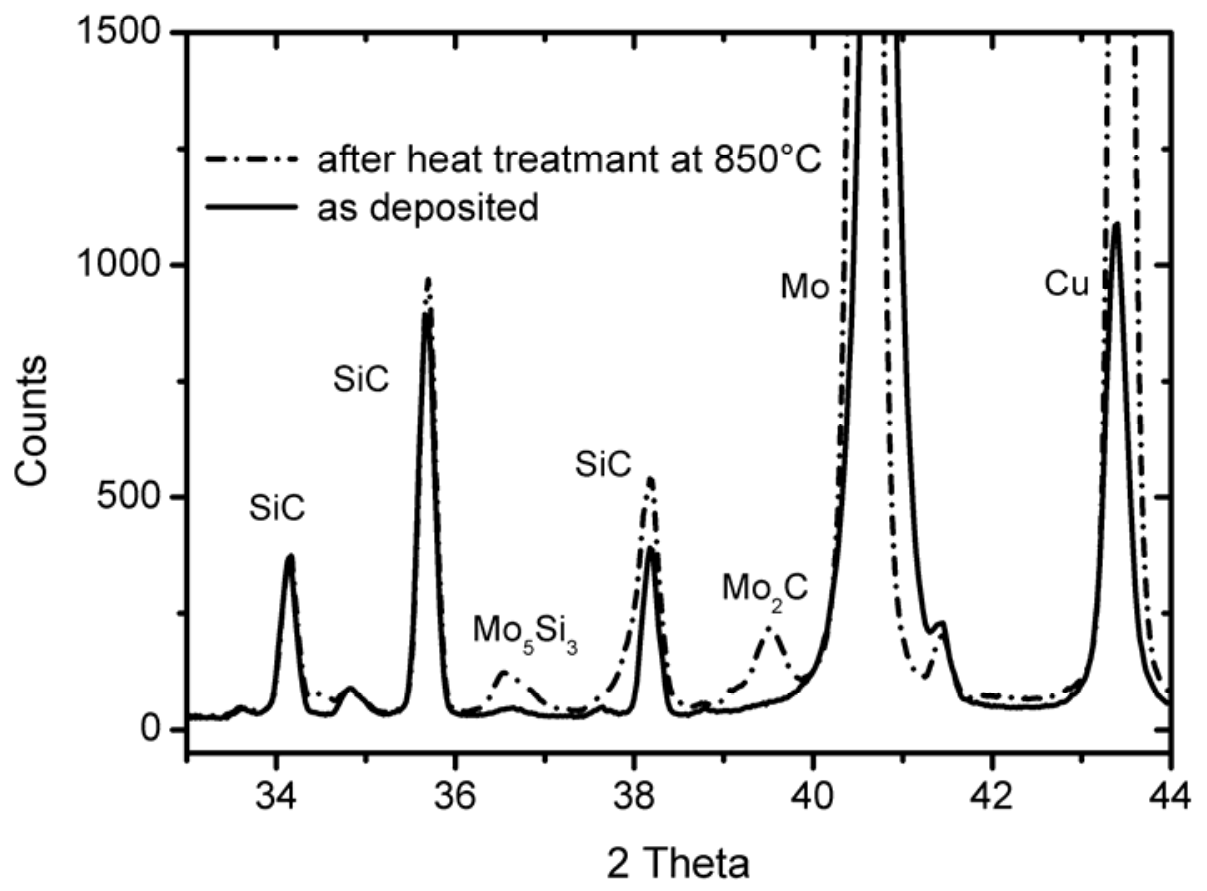


Figure 6
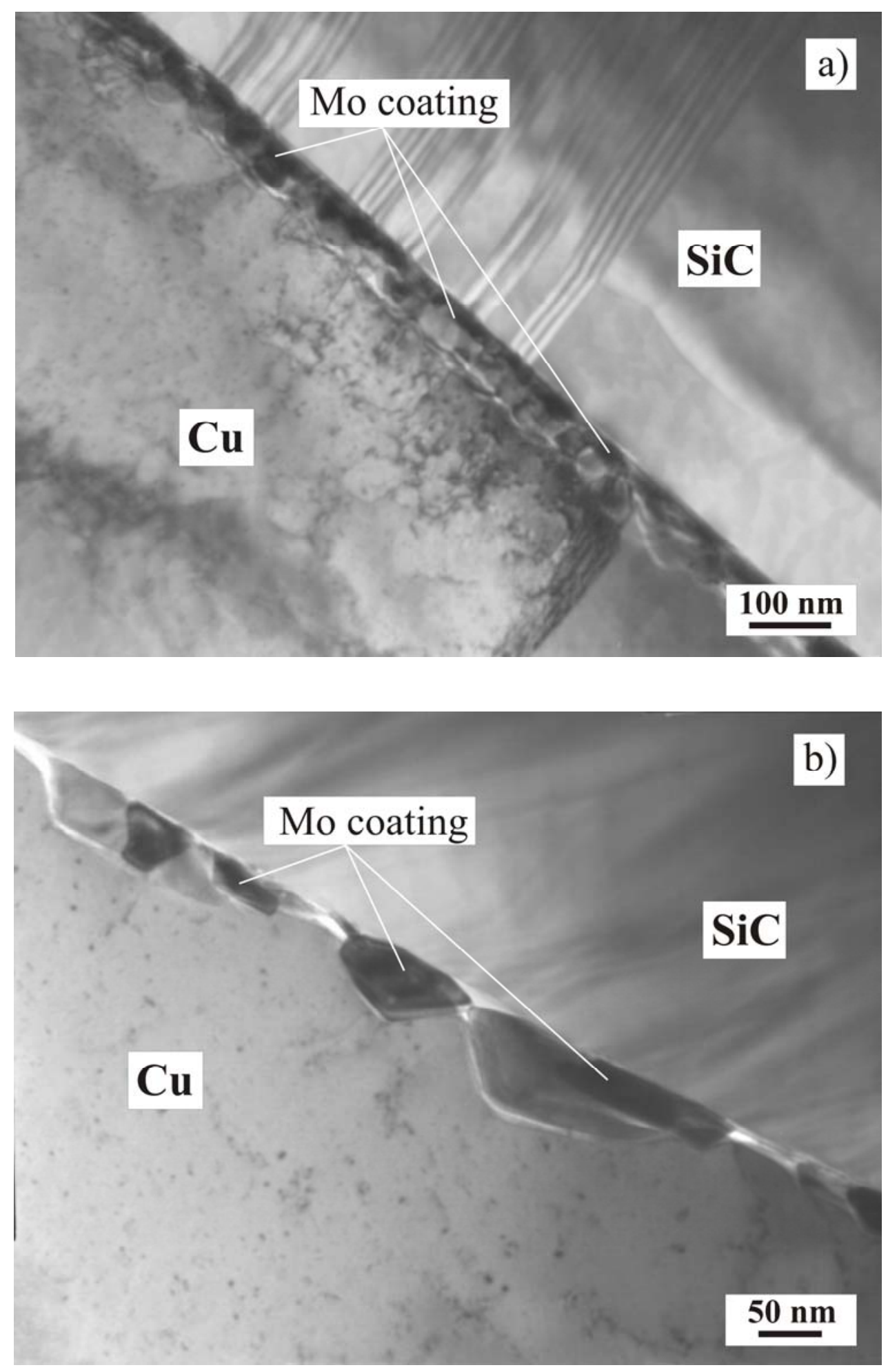
Figure 7
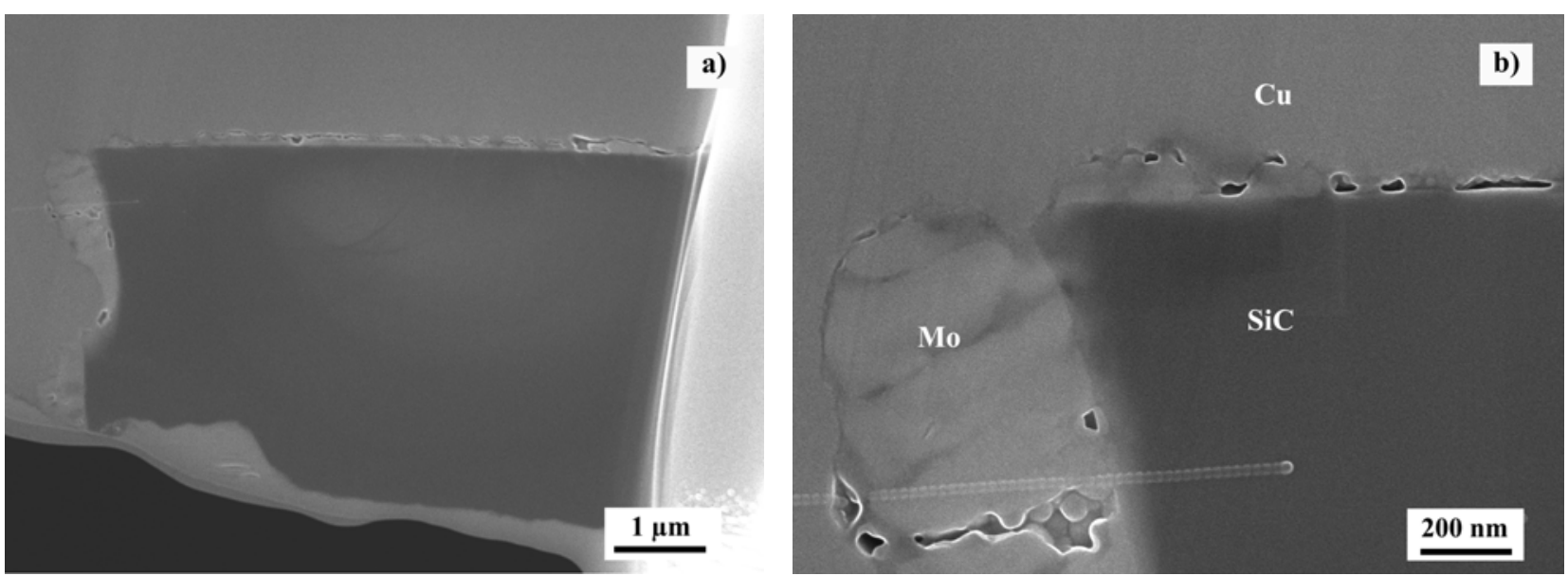

Figure 8

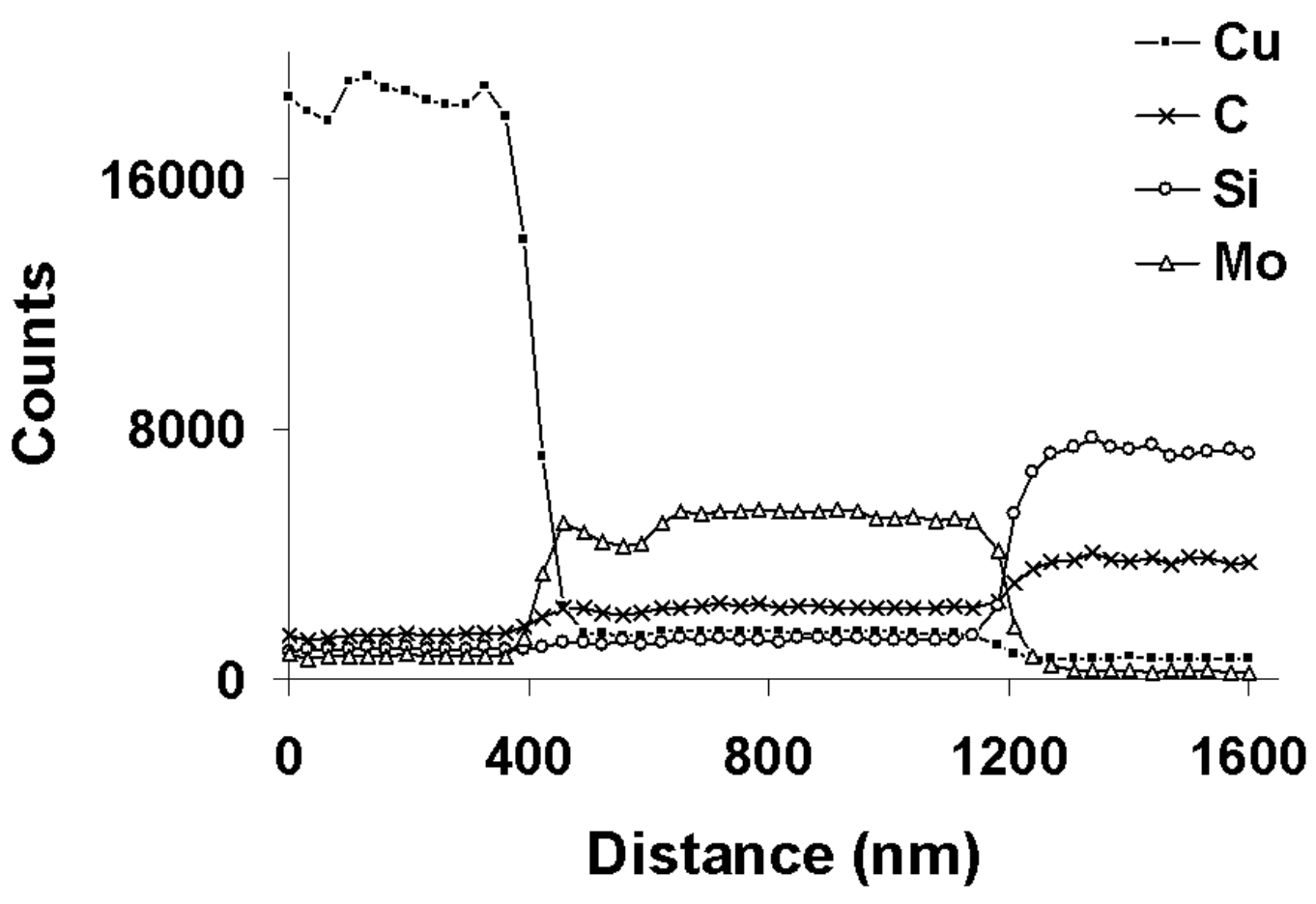

